\title{
O PETICIONAMENTO INDIVIDUAL E O SISTEMA INTERAMERICANO DE DIREITOS HUMANOS: OS MECANISMOS ALTERNATIVOS CONTRA VIOLAÇÕES DE DIREITOS
}

\section{THE PETITIONING INDIVIDUAL AND THE INTER-AMERICAN SYSTEM HUMAN RIGHTS: ALTERNATIVE MECHANISMS AGAINST RIGHTS VIOLATIONS}

\author{
${ }^{1}$ Sílvia Leiko Nomizo \\ ${ }^{2}$ Bruno Augusto Pasian Catolino
}

\section{RESUMO}

Os sistemas de proteção internacional dos direitos humanos se desenvolvem tanto no âmbito internacional, pelas regulamentações da Organização das Nações Unidas, quanto no âmbito regional, por meio dos organismos regionais de proteção destes direitos. Ambos os sistemas (internacional e regional) são complementares, de forma para uma efetiva proteção dos direitos humanos em nível global devem ser criados e aperfeiçoados os mecanismos de acesso à justiça internacional. O presente trabalho objetiva abordar o processo de justicialização do sistema interamericano através do mecanismo de petições, na forma direta, por meio de grupos ou indivíduos para os órgãos responsáveis, propondo uma reflexão a respeito das inovações, avanços e desafios contemporâneos de tal aparato de proteção dos direitos humanos, uma vez que o Brasil é signatário da maioria dos todos os Tratados e Convenções Internacionais sobre Direitos Humanos. Contudo, de forma contraditória, a maciça adesão a tais documentos internacionais não reflete a uma evolução interna na proteção dos direitos humanos. Como metodologia adotada a pesquisa se pauta pelo método indutivo no que concerne a abordagem, eis que por intermédio do mecanismo de peticionamento individual, será analisada a sistemática da proteção internacional dos direitos humanos. Quanto ao procedimento observamos o método comparativo-histórico, e no procedimento, opta-se pela abordagem pela pesquisa bibliográfica e documental.

Palavras-chave: Sistema interamericano de direitos humanos, Peticionamento individual, Justicialização

\footnotetext{
${ }^{1}$ Mestranda em Direitopela Centro Universitário Euripedes de Marília - UNIVEM, São Paulo (Brasil). Professora pela Universidade Estadual de Mato Grosso do Sul - Unidade U. de Paranaíba - UEMS, Mato Grosso do Sul (Brasil). E-mail: leconomizo@yahoo.com.br

${ }^{2}$ Mestrando em Direito pela Centro Universitário Euripedes de Marília - UNIVEM, São Paulo (Brasil). Professor pela Universidade Estadual de Mato Grosso do Sul - Unidade U. de Paranaíba - UEMS, Mato Grosso do Sul (Brasil). E-mail: brunocatolino@yahoo.com.br
} 


\begin{abstract}
The international protection of human rights systems are developed both internationally, by regulations of the United Nations, as at the regional level, through the regional protection of these rights bodies. Both systems (international and regional) are complementary in order for effective protection of human rights on a global level should be established and improved the access to international justice mechanisms. This paper aims to address the justicialização of the inter-American system through the petitions mechanism in directly, through groups or individuals to the bodies responsible, proposing a reflection on the innovations, achievements and current challenges such protection apparatus human rights, since Brazil is a signatory of most all Treaties and International Conventions on Human Rights. However, in a contradictory way, the massive adherence to such international documents do not reflect the internal evolution in protecting human rights. As methodology research is guided by the inductive method with respect to approach, behold, through the individual petitioning mechanism, will be analyzed systematically the international protection of human rights. As for the procedure observe the comparative-historical method and procedure, the option is to approach the bibliographical and documentary research.
\end{abstract}

Keywords: Inter-american human rights system, Individual petitioning, Justice process 


\section{INTRODUÇÃO}

Inicialmente, pontua-se pela especificação da metodologia adotada no trabalho, para que se possa, após, adentrar ao mérito proposto nesta pesquisa.

No que se refere a metodologia do presente trabalho, este se pauta pelo método indutivo no que concerne a abordagem, eis que por intermédio do mecanismo de peticionamento individual, será indutivamente pensada a sistemática da proteção internacional dos direitos humanos. Quanto ao procedimento observamos o método comparativo-histórico, uma vez que se objetiva trazer as hipóteses, legitimidade e procedimentos do mecanismo do peticionamento individual e outros mecanismos correlatos.

Feitas a introdução correlata a metodologia, passemos ao mérito do trabalho.

Em uma análise breve, é pontual situar o início do atual modelo de proteção internacional de direitos humanos, que é inaugurado legalmente no período do pós-guerra, a partir da Declaração Universal dos Direitos Humanos de 1948 - momento em que inúmeros tratados internacionais voltados à proteção de direitos humanos são ratificados por diversos países.

Nesse sentido, PIOVESAN (2011b) leciona que o sistema internacional inaugura um modelo de ação para que os países possam encaminhar denúncias, caso estes "standards" internacionais sejam desrespeitados.

A partir da Declaração Universal, tem-se que os preceitos nela contidos são espalhados por todos os continentes, através de um movimento de elaboração de normas regionais de direitos humanos, trazendo a motivação humanística de 1948 a ser aplicada à problemática regional de segurança dos direitos fundamentais.

Considerando a divergência relacionada a força vinculante da Declaração Universal de Direitos Humanos, seja considerada como mera recomendação ou integrando o direito costumeiro internacional, com a edição do o Pacto Internacional dos Direitos Civis e Políticos e o Pacto Internacional dos Direitos Econômicos, Sociais e Culturais (ambos promulgados pela Assembleia Geral da ONU em 1996) houve a "juridicização" da legislação internacional humanística, por ambos os documentos possuírem força vinculante, obrigando aos Estados que o ratificarem ao cumprimento de seus termos.

O mecanismo de peticionamento individual para os órgãos de proteção internacional, principalmente para a Comissão e a Corte Interamericana de Direitos Humanos, é algo de efetividade recente no âmbito brasileiro. 
Neste sentido, vejam-se as notícias destes últimos meses $^{1}$, em que a Corte Interamericana de Direitos Humanos notificou o Estado Brasileiro pelo não cumprimento das obrigações impostas por meio da sentença no processo "Gomes Lund” contra a República Federativa do Brasil.

Dentre tais obrigações e medidas não tomadas pelo Brasil, estão: a manutenção da Lei de Anistia como empecilho de investigação e interposição de ações penais contra os agentes estatais que cometeram crimes no período; por mais eficiência nos grupos que investigam ossadas e restos mortais dos desaparecidos no Araguaia; para que o país continue se esforçando para tipificar o crime de desaparecimento forçado; que esclareça a maneira como vai assegurar a participação de familiares de vítimas em todas as etapas da investigação e julgamento dos responsáveis; ministrar cursos de direitos humanos nas Forças Armadas; ratifique as resoluções da ONU e da OEA sobre desaparecimentos forçados (CORTE IDH, 2014).

Ademais, há certa imprevisibilidade e dificuldade sobre a execução das decisões da Corte Interamericana de Direitos Humanos, porque é sabido que o STF na ADPF 153 considerou válida e recepcionada a Lei de Anistia de 1979, conflitando frontalmente com a decisão proferida pela Corte Interamericana.

Neste sentido, há que se perquirir a compatibilização entre os sistemas nacional e internacional de direitos humanos, e os limites que decorrem de cada um.

\section{A PROTEÇÃO DOS DIREITOS HUMANOS EM ÂMBITO GLOBAL}

A partir da juridicização da legislação internacional, cria-se o que se convencionou nomear como sistema global de proteção dos direitos humanos. Evidentemente, a partir deste momento histórico e político, outros documentos internacionais foram editados, principalmente no que se refere às violações de direitos fundamentais específicos, tais quais a

\footnotetext{
${ }^{1}$ Dentre os diversos sites de notícias que publicaram o ocorrido, citamos os seguintes sítios eletrônicos: http://oglobo.globo.com/brasil/corte-da-oea-notifica-brasil-por-nao-avancar-na-investigacao-dedesaparecimentos-no-araguaia-14710212;

http://www1.folha.uol.com.br/fsp/poder/198437-corte-critica-brasil-por-nao-investigar-mortes-noaraguaia.shtml;

http://carlosamorim.com/2014/12/05/a-oea-adverte-o-brasil-nao-cumpriu-sentenca-internacional-sobre-crimespoliticos-em-2010-a-corte-interamericana-de-direitos-humanos-condenou-o-pais-por-mortos-e-desaparecidosdurante-o-regime-militar/
} 
Convenção Internacional sobre a Eliminação de todas as formas de Discriminação Racial (1969), Convenção Internacional sobre a Eliminação de todas as formas de Discriminação contra a Mulher (1979) e a Convenção Internacional contra a Tortura (1984), dentre outras.

Neste diapasão, os sistemas de proteção internacional dos direitos humanos se desenvolvem tanto no âmbito internacional, pelas regulamentações da Organização das Nações Unidas, quanto no âmbito regional, por meio dos organismos regionais de proteção destes direitos.

Ambos os sistemas (internacional e regional) são complementares, de forma que a observância de um, não inibe a estrita observância das disposições do outro. Também, não há qualquer forma de superioridade do sistema internacional para o regional. O internacional é o gerido pela ONU, enquanto que os sistemas de proteção regional estão ligados à União Europeia (EU), à União Africana (UA), e no Brasil, à Organização dos Estados Americanos (OEA).

O recorte metodológico do presente trabalho enfoca os mecanismos judicializantes do Sistema Interamericano de Direitos Humanos, eis que, conforme abaixo será melhor justificado abaixo, as grandes questões de proteção dos direitos fundamentais e humanos estão atualmente passando pelo crivo da Comissão e da Corte Interamericana de Direitos Humanos.

O Sistema Interamericano de Direitos Humanos tem como documento base a Convenção Americana de Direitos Humanos de 1969 (Pacto de San José da Costa Rica)². O documento entrou em vigor internacional em 18 de julho de 1978 e o Brasil depositou a carta de adesão em 25 de setembro de 1992, promulgando-a por meio do Decreto ${ }^{\circ} 678$ de 6 de novembro de 1992.

Conforme propõe PIOVESAN (2000), no prisma do Sistema Global de proteção dos direitos humanos, os sistemas geral e especial coexistem e são complementares. Ademais, o sistema geral de proteção, a exemplo da Declaração Universal dos Direitos do Homem, é endereçado a qualquer cidadão, de qualquer etnia, religião, orientação sexual, orientação política etc.

2 A Convenção foi adotada em São José (Costa Rica) em 22 de novembro de 1969 e entrou em vigor em 18 de julho de 1978. Atualmente conta com 25 Estados-partes com algumas exceções notáveis. Os Estados Unidos assinaram a Convenção em 1977, mas não a ratificaram, o Canadá não é signatário e a maioria dos países caribenhos de língua inglesa também não são. Com relação a esses países, a CIDH está avaliando seu histórico de direitos humanos à luz dos seus compromissos internacionais consagrados na Declaração Americana, da qual são signatários. 


\section{O BRASIL NO PANORAMA DOS TRATADOS E CONVENÇÕES INTERNACIONAIS DE DIREITO HUMANOS}

Conforme o pensamento de Hannah Arendt (1979), os direitos humanos não são um dado, mas um construído, uma invenção humana, em constante processo do pensar e do repensar.

Neste enfoque protetivo dos direitos humanos, o Brasil é signatário de praticamente todos os tratados internacionais. Os Tratados e Convenções Internacionais sobre Direitos Humanos têm relevância fundamental no ordenamento brasileiro, pela possibilidade de guardarem status constitucional, se aprovados com o quórum das emendas constitucionais (art.5 $5^{\circ}$ § $3^{\circ}$ da Constituição Federal de 1988).

Contudo, contraditoriamente, no Brasil, a evolução da adesão aos tratados internacionais de direitos humanos, não é acompanhada por uma proteção, e resolução destes conflitos, no âmbito interno. Ou seja, mesmo que o Brasil ratifica a maior parte dos Tratados Internacionais de Direitos Humanos, tal preocupação a nível internacional não é refletida internamente. Portanto, ainda há diversas violações aos direitos humanos.

A título exemplificativo, apontamos abaixo diversos dados, notícias, pesquisas e estatísticas, que indicam, que o Brasil ainda viola vários direitos fundamentais de seus cidadãos ou grupos de indivíduos.

No que se refere à violência, em um ranking de 95 países, o Brasil é, respectivamente, o oitavo com as maiores taxas de homicídios entre jovens na faixa de 15 a 24 anos, e o sétimo considerando a população total. Ressalte-se que neste ranking estão inclusos países como o Iraque, que ocupa o $23^{\circ}$ lugar (WAISELFISZ, 2014).

Em relação a atual crise hídrica vivenciada pelo país, em entrevista ao jornal Folha de São Paulo, a relatora da ONU, Catarina de Albuquerque, aduziu que há violação de direitos humanos na atual crise hídrica brasileira (FOLHA ON LINE, 2014).

No que se refere a jurisdição, é notória a condenação do Estado Brasileiro pela Comissão Interamericana de Direitos Humanos - CIDH - no caso ${ }^{\circ} 11.552$ - Julia Gomes Lund - Guerrilha do Araguaia (OAS, 2014a) ${ }^{3}$.

\footnotetext{
${ }^{3}$ Em relação a este critério, importante mencionar as submissões recentes de outros casos à Corte Interamericana de Direitos Humanos: Caso Garibaldi VS. Brasil, Caso Ximenes Lopes VS. Brasil, Caso Escher e outros VS. Brasil referentes a Supervisão de Cumprimento de Sentença, e Caso Unidade de Intervenção Sócio-Educativa de Cariacica, Espírito Santo e Caso Penitenciária "Dr. Sebastião Martins Silveira" em Araraquara, São Paulo, referentes a Medidas Provisórias.
} 
Temos também a, não menos importante, questão da instalação da usina hidroelétrica de Belo Monte, objeto de deliberação internacional pela Comissão Interamericana de Direitos Humanos que emitiu a Medida Cautelar 382/10 para suspender as obras, dentre outros, para que houvesse um adequado estudo socioambiental na região, em especial para a adequada proteção aos grupos indígenas que habitam a região (CIDH, 2014).

Da mesma forma, vem sendo questionada a possibilidade de haver a análise pela Corte Interamericana de Direitos Humanos da sentença proferida na Ação Penal 470 (BOZO, 2013). É também de conhecimento público a comunicação à Comissão Interamericana de Direitos Humanos sobre a desocupação dos moradores do "Pinheirinho", em São José dos Campos, e da medida cautelar (deferida pela CIDH - MC n ${ }^{\circ}$ 367/2013) para preservação da vida dos detentos na penitenciária de "Pedrinhas", no Maranhão (OAS, 2014b).

Portanto, os maiores problemas nacionais, relacionados ao Direito, de uma forma geral, acabam sendo analisados, hodiernamente, por uma perspectiva da proteção internacional dos direitos humanos, sendo que a análise deste processo e das vias alternativas na solução de conflitos é imperiosa.

\section{A JUSTICIALIZAÇÃO E OS MECANISMOS DE ACESSO A JUSTIÇA NA ESFERA INTERNACIONAL}

De todos os exemplos narrados acima, há que se destacar a justicialização do sistema interamericano de direitos humanos. O termo justicialização significa a existência de mecanismos que permitam o julgamento dos Estados pelos órgãos internacionais.

Assim, de acordo com o Regulamento da Comissão Interamericana de Direitos Humanos (REGULAMENTO, 2013), caso a Comissão considerar que o Estado não cumpriu suas recomendações (de acordo com os artigos 45 e 74), esta submeterá o caso à Corte Interamericana.

Flávia Piovesan (2006, p.58) ressalta a necessidade de justicialização dos direitos humanos, bem como a expansão dos mecanismos de peticionamento individual:

“[...] se, de um lado, faz-se necessária a justicialização dos direitos humanos, por outro é emergencial ampliar a capacidade processual do indivíduo no sistema internacional, mediante sua democratização. Isto é a afirmação de instâncias jurisdicionais de proteção internacional dos direitos humanos deve ser conjugada com a consolidação do indivíduo como verdadeiro sujeito de direito no campo internacional. Há que se fortalecer o acesso à justiça internacional”. (PIOVESAN, 2006, p. 58) 
Observa-se, portanto, que a agenda política brasileira, hodiernamente, assim como em outros países, deve pautar-se pelo respeito aos direitos humanos, e vislumbra-se que os organismos internacionais, em várias situações como algumas acima exemplificadas, se utilizam dos expedientes legais internacionais para fiscalizarem o compromisso com a proteção aos direitos humanos pelo Brasil.

Justifica-se, neste sentido, a abordagem do processo de justicialização do sistema interamericano através do mecanismo de petições, na forma direta, por meio de grupos ou indivíduos para os órgãos responsáveis, propondo uma reflexão a respeito das inovações, avanços e desafios contemporâneos de tal aparato de proteção dos direitos humanos.

A abordagem deste processo, ainda em tramite, da crescente justicialização, tem necessidade, portanto, como um mecanismo alternativo de proteção dos direitos humanos, além do que, como já foi ressaltado, também se faz necessária pelo destaque que os mecanismos de comunicação/peticionamento aos órgãos internacionais de direitos humanos têm atualmente (a exemplo das diversas comoções políticas intestinas que, de forma direta ou indireta, vem sendo objeto de questionamento e proteção pela Comissão Interamericana de Direitos Humanos e Corte Interamericana de Direitos Humanos).

\section{OS MECANISMOS CONVENCIONAIS E EXTRA-CONVENCIONAIS DE PROTEÇÃO AOS DIREITOS HUMANOS}

De uma forma geral, existem dois mecanismos de proteção a direitos humanos no âmbito global, os mecanismos convencionais e os extra-convencionais. Os convencionais são os criados pelas convenções específicas de direitos humanos, como a Convenção pela Eliminação de Todas as Formas de Discriminação Racial, a Convenção pela Eliminação de Todas as Formas de Discriminação contra a Mulher, o Pacto Internacional sobre Direitos Civis e Políticos, dentre outras.

Os órgãos de proteção criados por tais documentos internacionais têm competência para analisar relatórios e petições individuais apenas de Estados que ratificaram a convenção instituidora do órgão. Já os mecanismos extra-convencionais advêm principalmente da Carta da ONU, e podem receber petições individuais de países que não tenham ratificado nenhuma convenção específica de direitos humanos, além de poderem tratar sobre violações de quaisquer direitos, contanto que relacionados a violações sistemáticas (IKAWA, 2014). 
Portanto, a proposta do presente trabalho tem o recorte metodológico na ocupação do Sistema Interamericano de Direitos Humanos, com a indicação do mecanismo de peticionamento individual como alternativa posta aos indivíduos e grupos de pessoas contra as violações de direitos humanos no âmbito interno destes países.

Outra análise, igualmente interessante seria perquiriras hipóteses em que tais comunicações/petições terão legitimidade para serem apreciadas pelos organismos internacionais competentes, seja na esfera interamericana, ou no domínio universal. Contudo, nesta oportunidade, optamos por não enfocar a questão do peticionamento individual em outros Sistemas de Proteção, tais quais o Africano, Asiática e Europeu.

\section{OS MECANISMOS DE IMPLEMENTAÇÃO DOS DIREITOS HUMANOS INTERNACIONAIS (RELATÓRIOS, COMUNICAÇÕES E O PETICIONAMENTO INDIVIDUAL)}

Como principais instrumentos para a implementação dos direitos assegurados nos documentos internacionais sobre direitos humanos, ressaltam-se os relatórios, as comunicações e as petições individuais. De forma sucinta, conforme o Regulamento da Comissão Interamericana de Direitos Humanos, respectivamente, podemos definir os conceitos de cada instrumento.

O Relatório (art.59) consiste em uma "análise da situação dos direitos humanos [...], acompanhada das recomendações aos Estados e aos órgãos da Organização sobre as medidas para fortalecer o respeito aos direitos humanos [...]". A comunicação (arts. 36, 39, 50 e 73), é outra forma de acesso aos órgãos protetivos internacionais, para que uma Comissão possa intervir caso haja alguma violação de algum direito humano, inclusive com visitas in loco, para melhor se apurar a violação de direitos.

Por fim, as petições individuais, são mecanismos postos à disposição de qualquer cidadão para que acione os órgãos de proteção internacionais com o intuito de que haja uma efetiva proteção dos direitos humanos, na hipótese de, internamente, o Estado não prestar a proteção necessária aos sujeitos.

Por serem objeto de destaque neste trabalho, convém transcrevermos integralmente o artigo 23 e 51 do Regulamento da Comissão Interamericana de Direitos Humanos, que disciplina o peticionamento individual, e também coletivo, para os órgãos internacionais: 
Artigo 23. Apresentação de petições

Qualquer pessoa ou grupo de pessoas, ou entidade não-governamental legalmente reconhecida em um ou mais Estados membros da Organização pode apresentar à Comissão petições em seu próprio nome ou no de terceiras pessoas, sobre supostas violações dos direitos humanos reconhecidos, conforme o caso, na Declaração Americana dos Direitos e Deveres do Homem, na Convenção Americana sobre Direitos Humanos "Pacto de San José da Costa Rica", no Protocolo Adicional à Convenção Americana sobre Direitos Humanos em Matéria de Direitos Econômicos, Sociais e Culturais "Protocolo de San Salvador", no Protocolo à Convenção Americana sobre Direitos Humanos Referente à Abolição da Pena de Morte, na Convenção Interamericana para Prevenir e Punir a Tortura, na Convenção Interamericana sobre o Desaparecimento Forçado de Pessoas, e na Convenção Interamericana para Prevenir, Punir e Erradicar a Violência contra a Mulher, em conformidade com as respectivas disposições e com as do Estatuto da Comissão e do presente Regulamento. O peticionário poderá designar, na própria petição ou em outro instrumento por escrito, um advogado ou outra pessoa para representá-lo perante a Comissão.

\section{$[\ldots]$}

Artigo 51. Recebimento da petição

A Comissão receberá e examinará a petição que contenha denúncia sobre presumidas violações dos direitos humanos consagrados na Declaração Americana dos Direitos e Deveres do Homem com relação aos Estados membros da Organização que não sejam partes da Convenção Americana sobre Direitos Humanos.

Outra prescrição importante, previsto no Regulamento é que em casos graves e urgentes, a Comissão poderá realizar uma investigação in loco mediante consentimento prévio do Estado em cujo território se alegue haver sido cometida a violação, tão somente com a apresentação de uma petição ou comunicação que reúna todos os requisitos formais de admissibilidade - conforme artigo 39 do referido Regulamento.

Importe noção do mecanismo de peticionamento nos traz ENGSTROM (2011, p.105 in PAYNE; ABRÃO; TORELLY):

O Sistema Interamericano de Direitos Humanos (IAHRS, em inglês) surgiu como uma entidade quase judicial, com mandato mal definido, com vistas a promover o respeito aos direitos humanos na região. Consiste em um regime jurídico formal que permite aos cidadãos apresentar petições com a finalidade de contestar as atividades domésticas de seu próprio governo. O acesso dos indivíduos ao regime de direitos humanos tem sido fortalecido ao longo do tempo - à medida que o sistema evoluiu para um regime jurídico com enfoque processual na força da argumentação jurídica e na geração de jurisprudência regional de direitos humanos. Na sequência da transição para a democracia na América Latina, a evolução do IAHRS ficou ligada à questão de como lidar com as violações dos direitos humanos ocorridas nos regimes anteriores 
Sobre o sistema de petições, o ex-juiz da Corte Internacional de Justiça, Antônio Augusto Cançado Trindade (2013, p.27-28) leciona:

Os tribunais internacionais de direitos humanos têm, muito compreensivelmente, buscado favorecer o acesso direto dos indivíduos a suas respectivas jurisdições. A Corte Europeia de Direitos Humanos já o logrou, a partir da entrada em vigor, em $1^{\circ} .11 .1998$, do Protocolo n. 11 à Convenção Europeia de Direitos Humanos. A Corte Interamericana de Direitos Humanos tem dado passos significativos neste sentido, sobretudo mediante as modificações introduzidas no seu quarto Regulamento - de que fui relator da CTIADH (que entrou em vigor em $1^{\circ} .6 .2001$ ), contendo o avanço mais relevante da operação do mecanismo de proteção da Convenção Americana sobre Direitos Humanos de 1969 desde sua entrada em vigor em

1978. A nova Corte Africana de Direitos Humanos e dos Povos tem dado mostras de seguir adiante na mesma direção. A posição que tenho sempre sustentado a esse respeito é no sentido de que há uma verdadeira linha de evolução - que cabe sustentar - que tem resgatado a posição dos indivíduos como verdadeiros sujeitos do direito internacional dos direitos humanos, assim como do direito internacional público (e não como simples objetos de proteção), dotados de plena capacidade jurídica para atuar (legitimatio ad causam) no plano internacional (locusstandi in judicio e jus standi). Os indivíduos peticionários são a verdadeira parte demandante perante os tribunais internacionais de direitos humanos. A jurisdição obrigatória dos tribunais internacionais de direitos humanos é, em meu entender, o complemento indispensável do direito de petição individual internacional; constituem eles os pilares básicos da proteção internacional, do mecanismo de emancipação do ser humano vis-à-vis seu próprio Estado. Afiguram-se eles como verdadeiras cláusulas pétreas da proteção internacional da pessoa humana.

Portanto, podemos observar que o Sistema Interamericano de Proteção dos Direitos Humanos teve o cuidado de preservar a capacidade processual individual, ou seja, a legitimidade ativa de cidadãos nacionais do Estado-parte para postular em juízo se houver violação de seus termos. Neste sentido, vem sendo comum que grupos, indivíduos ou os próprios Estados acionem judicialmente o Sistema Internacional de Proteção aos Direitos Humanos para que haja a proteção de seus direitos.

\section{A PRINCIPIOLOGIA DO PROCESSO DE INTERNACIONALIZAÇÃO DOS DIREITOS HUMANOS E A NECESSIDADE DE REVISÃO DO CONCEITO TRADICIONAL DE SOBERANIA ESTATAL}

No que concerne à lógica e a principiologia do processo de internacionalização dos direitos humanos, deve-se investigar a forma pela qual este tem se tornado a herança da "Era dos Direitos", conforme já investigado por Bobbio (2004). 
O nível do impacto no ordenamento jurídico interno dos Estados pela atividade do Sistema Interamericano, em especial da jurisdição da Corte Interamericana como um instrumento de um constitucionalismo internacional e pela imposição de parâmetros mínimos de proteção na área dos direitos humanos, também é importante para que se possa, com segurança, afirmar quais os reais limites que uma "Justiça Internacional” possui.

Realizar um estudo sobre a necessidade de revisão do conceito tradicional de soberania dos Estados, na medida em que são admitidas intervenções no plano nacional em prol da proteção dos direitos humanos, portanto, é de extremo interesse para a evolução protetiva internacional.

Além disso, tem-se que a investigação do mecanismo de adesão dos Protocolos Facultativos nos documentos internacionais, bem como a sistemática de monitoramento e implementação dos direitos protegidos, para averiguar a amplitude jurídica dos documentos internacionais, é igualmente relevante.

Interessante, neste sentido, o entendimento de Antônio Augusto Cançado TRINDADE (2003), em que o pensador defende o aperfeiçoamento dos mecanismos de proteção internacional, e em especial, o peticionamento individual como meio de ampliação protetiva dos direitos humanos.

Neste sentido, e nesta defesa, se depositam as pesquisas de Flávia Piovesan e Augusto Antônio Cançado Trindade.

Flávia Piovesan (2011a) defende que um equânime Sistema Internacional de Proteção dos Direitos Humanos tem o condão de redefinir o conceito da cidadania no Brasil justamente porque estes novos mecanismos de acesso à justiça internacional podem alterar a relação que o Estado tem com seus concidadãos.

\section{O APERFEIÇOAMENTO DOS MECANISMO DE PETICIONAMENTO INDIVIDUAL COMO MEIO DE EFETIVAÇÃO DA INTERNACIONALIZAÇÃO DOS DIREITOS HUMANOS}

Enfatiza-se que o aperfeiçoamento dos mecanismos de peticionamento individual aos órgãos de proteção aos direitos humanos se apresenta como parte importante do processo de internacionalização dos direitos humanos e da interconstitucionalização destes direitos. Os Estados que desejam ser parte dos sistemas de proteção internacionais, ratificando os documentos internacionais protetivos, devem se adequar e propiciar meios que seus cidadãos tenham acesso a tais mecanismos. 
O Brasil, especificamente nestes tempos de efetivação da coercibilidade e da vinculação das decisões internacionais, inclusive com penalidades ao Estado que se recusar a cumprir as decisões, terá que discutir e encontrar uma solução em adequação ao novo quadro de justicialização operada.

A exemplo disso, para que o Brasil possa cumprir as determinações estipuladas pela Corte Interamericana de Direitos Humanos (exigências na condenação do caso Gomes Lund), ou não cumprir; há que se discutir o papel e a força das determinações judiciais de nível internacional. Caso contrário, há que se observar apenas suas decisões judiciais internas (Supremo Tribunal Federal), destoando assim deste processo de crescente justicialização dos direitos humanos em âmbito internacional.

\section{CONCLUSÃO}

Após a célebre Declaração de Direitos Humanos da ONU, com a resolução parcial da questão judaica, dada a criação do Estado de Israel, em 1948, tangente àquele grupo étnicosocial específico, a questão da proteção dos direitos humanos em nível internacional hibernou na agenda internacional. A inércia da ONU nas questões de proteção de minorias, e aos direitos humanos de forma geral, foi devido tanto ao embate político-ideológico decorrente da Guerra Fria, quanto em virtude do enfoque individualista e universalista dos direitos humanos.

Explicar o porquê de tal inércia não deve ser o único foco para a análise da efetividade dos mecanismos de proteção internacionais dos direitos humanos. Indubitavelmente, deve haver uma multidimensionalidade na análise dos mecanismos de acesso à justiça relacionada à proteção da pessoa humana, independente de qual nacionalidade seja. $\mathrm{O}$ aspecto cosmopolita destes direitos humanos internacionais reveste o cidadão como sujeito de direitos a nível universal de proteção. Logo, mesmo que algum Estado não tenha mecanismos eficientes para proteger seu cidadão, cabe aos órgãos internacionais oferecerem uma efetiva proteção.

Apesar de que as preocupações internacionais na proteção dos direitos humanos foram renegadas a segundo plano, sendo que os direitos específicos das minorias somente foram declarados, no plano internacional, pelas diversas Declarações e Documentos listados pela Organização das Nações Unidas, o processo de justicialização dos direitos humanos parece ser caminho que não tem volta. 
A evolução e o próprio futuro de uma efetiva proteção dos direitos humanos, deve passar pela internacionalização desta proteção. Em um mundo no qual as fronteiras são cada vez mais relativas, há que pensar em mecanismos globais de proteção dos direitos humanos. Permitir o acesso de cidadãos de qualquer parte do mundo a estes meios é uma forma valiosa, e muitas vezes única (vide os conflitos étnicos e as guerras civis em países africanos tais quais Ruanda e Uganda) de proteger as pessoas contra o arbítrio estatal.

\section{REFERÊNCIAS}

ARENDT, Hannah. As Origens do Totalitarismo, trad. Roberto Raposo, Rio de Janeiro, 1979.

BOAS, Franz. Os métodos da etnologia. In: CASTRO (Org.). Antropologia Cultural. 6. ed. Rio de Janeiro: Zahar, 2010.

BOBBIO, Norberto. A era dos direitos (tradução Carlos Nelson Coutinho). Rio de Janeiro: Elsevier, 2004.

BOZO, Aline Maria Hagers; NICZ, Alvacir Alfredo. Reflexões acerca da Ação Penal 470 e a possibilidade de revisão pela Corte Interamericana de Direitos Humanos. Revista Fundação Argumenta - UENP. Jacarezinho, nº 19, p. 83-102. 2013.

BRASIL. Constituição Federal de 1988. Disponível em: <http://www.planalto.gov.br/ccivil_03/constituicao/ConstituicaoCompilado.htm>. Acesso em: 15 nov. 2014.

CIDH. Medidas cautelares outorgadas pela CIDH no ano 2011. Disponível em: <http://www.cidh.org/medidas/2011.port.htm>. Acesso em 20 nov 2014.

COMPARATO, Fábio Konder. A afirmação histórica dos direitos humanos. 4. ed., rev. e atual. São Paulo: Saraiva, 2005. 
CORTE IDH. Resolución de la corte interamericana de derechos humanos de 17 de octubre de 2014. Disponível em

<http://www.corteidh.or.cr/docs/supervisiones/gomes_17_10_14.pdf>. Acesso em $01 \mathrm{dez}$ 2014.

ENGSTROM, Par. A Anistia e o Sistema Interamericano de Direitos Humanos. In: A anistia na era da responsabilização: o Brasil em perspectiva internacional e comparada. PAYNE, Leigh A; ABRÃO, Paulo; TORELLY, Marcelo D. Brasília: Ministério da Justiça, Comissão de Anistia; Oxford: Oxford University, Latin American Centre, 2011.

FOLHA ON LINE. Falta de água é culpa do governo de SP, afirma relatora da ONU.Disponível em: <http://www1.folha.uol.com.br/cotidiano/2014/08/1508504-falta-deagua-e-culpa-do-governo-de-sp-afirma-relatora-da-onu.shtml>. Acesso em 05 dez. 2014.

IKAWA, Daniela. Acesso aos mecanismos extra-convencionais de proteção aos direitos humanos. Disponível em: <http://www.dhnet.org.br/direitos/sip/onu/textos/ikawa_mec_extra_convencionais_dh.pdf>. Acesso em 15 nov. 2014.

OAS. Caso 11.552, Julia Gomes Lund e outros (Guerrilha do Araguaia) contra a $\begin{array}{lllll}\text { República } & \text { Federativa } & \text { do } & \text { Brasil. } & \text { Disponível }\end{array}$ $<$ http://www.oas.org/pt/cidh/decisiones/corte/Caso11552port.doc $>$. Acesso em 20 nov de 2014a.

Personas Privadas de Libertad em el "Complexo Penitenciario de Pedrinhas" respecto de Brasil 16 de diciembre de 2013. Disponível em <http://www.oas.org/es/cidh/decisiones/pdf/MC367-13Resolucion11-13-es.pdf>. Acesso em 21 nov de $2014 b$.

PIOVESAN, Flávia. Direitos humanos globais, Justiça internacional e o Brasil. Revista Fundação Escola Superior do Ministério Público do Distrito Federal e Territórios. Brasília, Ano 8, V. 15, p. 93 - 110, jan/jun. 2000. 
Direitos humanos e o Direito Constitucional Internacional. 12. ed. rev. atual. São Paulo: Saraiva, 2011a.

Direitos humanos e justiça internacional: um estudo comparativo dos sistemas regionais europeu, interamericano e africano. São Paulo: Saraiva, 2006.

O Sistema Internacional dos Direitos Humanos no Brasil. Disponível em: <http://www.dhnet.org.br/dados/relatorios/dh/br/jglobal/jglobal2000/osistemainternacional.ht ml>. Acesso em 23 out. 2011b.

REGULAMENTO da Comissão Interamericana de Direitos Humanos de 2013. Disponível em: <http://www.cidh.org/Basicos/Portugues/u.Regulamento.CIDH.htm>. Acesso em 05 mai. 2015.

TRINDADE, Antônio Augusto Cançado. Os tribunais internacionais contemporâneos. Brasília: FUNAG, 2013.

. Tratado de direito internacional dos direitos humanos. Porto Alegre: SAFE, 2003.

WAISELFISZ, Julio Jacobo. O Mapa da Violência 2014 - Os jovens do Brasil (versão preliminar). Brasília: FLACSO, 2014. Disponível em:

<http://www.mapadaviolencia.org.br/pdf2014/Mapa2014_JovensBrasil_Preliminar.pdf>. Acesso em 01 dez 2014. 